\title{
Editorial
}

\section{Interdisciplinariedad, internacionalidad, interactividad. Eä: publicación, difusión y colaboración científica 2.0}

\section{Interdisciplinarity, internationality, interactivity.Ea: publication, dissemination and scientific collaboration}

\section{Internacionalidade, a interdisciplinaridade, a interatividade. Ea: divulgação, publicação e colaboração na investigação}

\author{
Gabriela Mijal Bortz
}

Directora Editorial de Eä - Revista de Humanidades Médicas \& Estudios Sociales de la Ciencia y la Tecnología. Asistente de Investigación en Instituto de Estudios sobre la Ciencia y la Tecnología, Universidad Nacional de Quilmes. gbortz@ea-journal.com

\section{Cómo citar este artículo en edición digital: Mijal Bortz, G. (2012) Interdisciplinariedad, internacionalidad, interactividad. Eä: publicación, difusión y colaboración científica 2.0. Cultura de los Cuidados. (Edición digital) 16, 32. Disponible en: <http:// dx.doi.org/10.7184/cuid.2012.32.01>}

El surgimiento y masificación de Internet ha abierto las puertas a nuevas formas de creación y difusión del conocimiento, generando una nueva cultura de comunicación, más ágil, y habilitando la posibilidad de interacción entre usuarios y grupos de usuarios, independientemente de la distancia geográfica. Las actuales tendencias se orientan hacia la construcción de saberes socializados y la generación y participación en espacios colaborativos. Desde hace algunos años ha proliferado una nueva generación de sitios, aplicaciones y servicios basados en el concepto de red, cuyo principal valor reside en la creación colectiva de contenidos por comunidades de usuarios.

Los medios de comunicación social interactiva (social media) han comenzado a tener notorias implicancias en el modo en el cual los investigadores se comunican y colaboran, ofreciendo una gran oportunidad para mejorar y optimizar su modo de trabajo facilitando la búsqueda, uso, aprovechamiento y difusión de información a través de un sinfín de herra- mientas. Los social media son asimismo utilizados para sortear las barreras disciplinarias, intercambiar información y formar núcleos de afinidad a nivel trasnacional.

En este contexto, Eä - Revista de Humanidades Médicas \& Estudios Sociales de la Ciencia y de la Tecnología, disponible en www. ea-journal.com, es una revista académica periódica en formato electrónico e interactivo que se propuso como misión conjugar el cumplimiento de altos estándares de excelencia académica, las exigencias de internacionalidad de un mundo globalizado, y la aplicación de las innovaciones de las nuevas Tecnologías de la Información y Comunicación (TICs) y redes sociales para publicación y difusión científica de las Humanidades Médicas y los Estudios Sociales de la Ciencia y la Tecnología.

Desde el comienzo (agosto de 2009), nuestro objetivo ha sido proponer un formato tecnológico innovador para la transmisión de los estudios situados en la confluencia entre salud, sociedad, ciencia y tecnología, así como tambi- 
én el desarrollo de una comunidad social académica en los campos especificados a través de la generación de herramientas colaborativas e interactivas dentro del sitio y su integración con espacios de intercambio en redes sociales. Asimismo, hemos seleccionado un abordaje interdisciplinario, puesto que consideramos que el análisis de los fenómenos en el ámbito de la salud son inescindibles de la sociedad en la que se desarrollan, y de las prácticas cognitivas y tecnológicas que en ella tienen lugar y que, a su vez, la transforman.

Conceptualmente, hemos pensado la revista como tres espacios diferenciados. El primero es el que denominaremos espacio académico. Dentro de éste se encuentran los contenidos académicos de la revista, los cuales son renovados cada cuatro meses (abril, agosto y diciembre) con cada nuevo número. Este espacio incluye una sección de archivo en la cual se encuentran disponibles los artículos publicados en los números anteriores y, por política editorial, todo el contenido es de libre acceso.

El principio rector de este espacio es la calidad académica. A estos efectos, Eä ha tomado como decisiones de política editorial: un riguroso mecanismo de selección de originales consistente en un referato externo realizado por pares a través de un sistema de doble ciego, que evalúa la pertinencia del tema para la revista, su originalidad, validez, importancia, el aporte realizado, claridad de expresión, metodología, conclusiones, resultados y bibliografía; un prestigioso comité editorial con una actividad académica ampliamente reconocida; cumplimiento de requisitos para la inclusión en índices internacionales, habiendo sido ya incluida en diversas bases de datos; adhesión a parámetros editoriales internacionales; $y$ auspicio académico por parte de la Asociación Médica Argentina (AMA) y de la Sociedad Ar- gentina de Historia de la Medicina (SAHIME).

En segundo lugar, podemos identificar un segundo espacio al cual denominaremos portal de noticias (Eä News). Éste es frecuentemente actualizado con noticias del ámbito académico: información sobre congresos y jornadas, nuevos recursos online, información sobre becas, premios y ofertas laborales para investigadores, así como también información propia de la revista, tal como la aparición de nuevos números, las aperturas de convocatorias a presentación de originales, la participación de Eä en eventos, la inclusión de nuevas herramientas o aplicaciones, y la aparición de nuevos artículos en nuestro blog, entre otras. La función informativa se extiende a su vez al tercer espacio.

A esta tercera área dentro del sitio nos referiremos como espacio colaborativo o interactivo. El portal de la revista incluye un sistema de registración a través del cual los usuarios pueden registrarse de forma gratuita y compartir información sobre eventos, nuevas publicaciones (libros y revistas), enlaces, recursos novedosos en línea, entre otras. Esta plataforma está orientada a facilitar a los lectores -en su gran mayoría investigadores- la posibilidad de, por un lado, informarse acerca de las multiplicidad de actividades y noticias en los campos de las Humanidades Médicas y los Estudios Sociales de la Ciencia y la Tecnología que se están llevando a cabo en todo el mundo y, por el otro, darles la posibilidad de compartir, dar a conocer y difundir dentro del sitio las actividades que ellos mismo están llevando a cabo y que puedan ser de interés de sus colegas en diversos países.

Dentro del sitio se han incorporado mecanismos de retroalimentación (feedback) y discusión, tales como la posibilidad de que los lectores comenten las noticias de la portada, 
un foro de discusión en el sitio y espacios propios en servicios de social networking y de microblogging, cuyos objetivos son transformarse en espacios de encuentro cotidiano entre investigadores. A través de distintas "salas de discusión" tanto en el sitio como en nuestros espacios en Facebook y en Twitter la idea es poder brindar diariamente noticias actualizadas de interés, y proveer un ámbito para discusiones académicas many-to-many, consultas, circulación de información y generación de proyectos conjuntos. La visión con la que fue creada esta aplicación es que la distancia geográfica sea un elemento de riqueza y diversidad, y no una barrera.

En tercer lugar, paulatinamente se han ido incorporando al sitio herramientas adicionales de forma integrada: los contenidos de la revista -tanto académicos como informativospueden ser compartidos a través de sistemas de marcadores sociales y de citación social. La revista permite además suscribirse a sus contenidos a través de herramientas de agregación (RSS) y recibir de forma instantánea las actualizaciones.

Finalmente, Eä ha inaugurado un espacio de blogging, EäBlog. Disponible en http:// blog.ea-journal.com, éste surgió a partir de la necesidad de contribuir a la circulación de los conocimientos y hallazgos de investigadores de todo en mundo en las disciplinas que se encuentran en la intersección entre salud, sociedad, ciencia y tecnología en ámbitos vastos, incluso por fuera del ámbito académico. El espacio es colaborativo, siendo los propios investigadores quienes dan a conocer ante un público amplio los resultados de su trabajo. Se ha buscado así profundizar la vehiculización de ideas y estimular el debate.

El vocablo Eä, que en la mitología tolkieniana significa tanto "el Mundo que Es" creado como el propio verbo creador $^{1}$, refleja para no- sotros la voluntad de crecimiento, renovación y creación que anima el día a día de nuestra publicación.

A lo largo de los seis números publicados en dos años de trabajo, han sido publicados 73 trabajos originales de investigación en cuatro idiomas distintos y hemos recibido las visitas de más de 27.000 lectores desde 148 países. Han sido difundidos más de 150 eventos de todo el mundo y publicadas más de 500 noticias. Con un espíritu de permanente iniciativa y dinamismo, Eä - Revista de Humanidades Médicas \& Estudios Sociales de la Ciencia y la Tecnología propone un nuevo modelo para la publicación, difusión y colaboración científica.

Buenos Aires, julio de 2011

\section{Agradecimientos:}

En nombre de Eä, quisiera agradecer a José Siles González por el honor de habernos invitado a participar de Cultura de los cuidados por medio de esta nota editorial.

\footnotetext{
${ }^{1}$ Véase Tolkien, J. R. R. (1984 [1977]). El Silmarillion. Barcelona: Minotauro.
} 